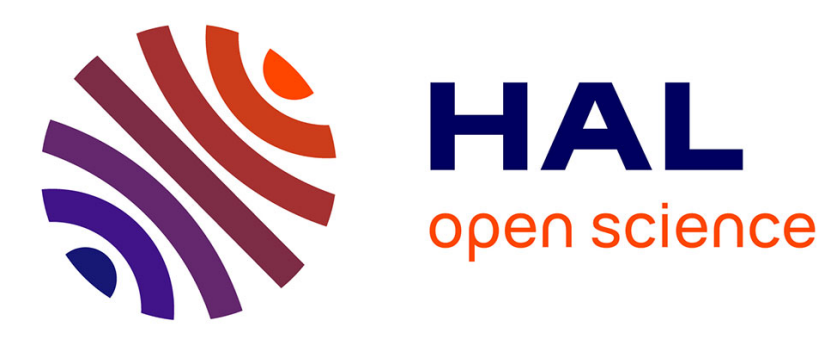

\title{
Physicochemical study of the hydrolysis of Rare-Earth elements (III) and thorium (IV)
}

Embarek Bentouhami, Gilles M Bouet, Jean Meullemeestre, François Vierling, Mustayeen A Khan

\section{- To cite this version:}

Embarek Bentouhami, Gilles M Bouet, Jean Meullemeestre, François Vierling, Mustayeen A Khan. Physicochemical study of the hydrolysis of Rare-Earth elements (III) and thorium (IV). Comptes Rendus. Chimie, 2004, 7 (5), pp.537-545. 10.1016/j.crci.2004.01.008 . hal-03225854

\section{HAL Id: hal-03225854 \\ https://univ-angers.hal.science/hal-03225854}

Submitted on 17 May 2021

HAL is a multi-disciplinary open access archive for the deposit and dissemination of scientific research documents, whether they are published or not. The documents may come from teaching and research institutions in France or abroad, or from public or private research centers.
L'archive ouverte pluridisciplinaire HAL, est destinée au dépôt et à la diffusion de documents scientifiques de niveau recherche, publiés ou non, émanant des établissements d'enseignement et de recherche français ou étrangers, des laboratoires publics ou privés. 


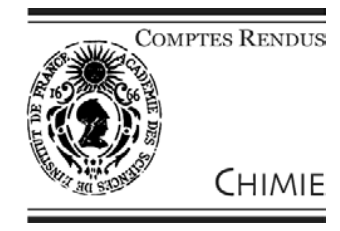

Preliminary communication / Communication

\title{
Physicochemical study of the hydrolysis of Rare-Earth elements (III) and thorium (IV)
}

\author{
Embarek Bentouhami ${ }^{\text {a }}$, Gilles M. Bouet ${ }^{\text {a }}$, Jean Meullemeestre ${ }^{\text {b }}$, \\ François Vierling ${ }^{\mathrm{b}}$, Mustayeen A. Khan ${ }^{\mathrm{a}, *}$
}

\footnotetext{
${ }^{a}$ Laboratoire de chimie de coordination, SONAS, UPRES EA 921, UFR Pharmacie, 16, bd Daviers, 49045 Angers cedex 01, France

${ }^{b}$ Ecole de chimie, polymères et matériaux (ECPM), UMR 7512, 25, rue Becquerel, BP 8, 67087 Strasbourg cedex 2, France
}

Received 10 July 2003; accepted after revision 8 January 2004

\begin{abstract}
The present work reports the hydrolysis of ions of the series of lanthanides (III) and actinide (IV) elements in dilute aqueous solutions. It has been systematically examined in the presence of sodium perchlorate, which has been used for maintaining the solution at constant ionic strength. The number, the nature of the species in solution and their hydrolysis $\operatorname{constants} \log \beta_{10 \mathrm{i}}$ for all ions at $I=0.1 \mathrm{~mol} \mathrm{dm}{ }^{-3}$ and at $25{ }^{\circ} \mathrm{C}$ were determined by different softwares: Superquad and Sirko_P. A pH-potentiometric method was used with glass electrodes to determine the equilibrium constants $K_{i}$ :
\end{abstract}

$\mathrm{M}^{n}+\mathrm{H}_{2} \mathrm{O} \rightleftharpoons \mathrm{M}(\mathrm{OH})^{(n-1)+}+\mathrm{H}^{+}$

where $\mathrm{M}^{n+}$ represents $\mathrm{Ce}^{3+}, \mathrm{Pr}^{3+}, \mathrm{Nd}^{3+}, \mathrm{Eu}^{3+}, \mathrm{Sm}^{3+}$ and $\mathrm{Th}^{4+}$ ions. For the lanthanides, hydrolysis increases with the increase of the atomic number and the contraction of the ionic radius. The $\mathrm{Th}^{4+}$ ion undergoes significant hydrolysis. To cite this article: E. Bentouhami et al., C. R. Chimie 7 (2004).

(C) 2004 Académie des sciences. Published by Elsevier SAS. All rights reserved.

\section{Résumé}

Cette étude concerne l'hydrolyse des ions de la série lanthanides (III) et du thorium (IV) ; elle a été effectuée en présence de perchlorate de sodium, utilisé pour maintenir constante la force ionique des solutions $I$, égale à $0,1 \mathrm{~mol} \mathrm{dm}^{-3}$. Le nombre et la nature des espèces en solutions, ainsi que leurs constantes d'hydrolyse $\log \beta_{10 \mathrm{i}}$, ont été déterminées à $25^{\circ} \mathrm{C}$ à l'aide de différents softwares de calculs, à savoir, Superquad et Sirko_P. Une méthode potentiométrique est utilisée sur électrode de verre pour déterminer les constantes d'équilibres $K_{i}$ :

$\mathrm{M}^{n}+\mathrm{H}_{2} \mathrm{O} \rightleftharpoons \mathrm{M}(\mathrm{OH})^{(n-1)+}+\mathrm{H}^{+}$

où $\mathrm{M}^{n+}$ représente les ions $\mathrm{Ce}^{3+}, \mathrm{Pr}^{3+}, \mathrm{Nd}^{3+}, \mathrm{Eu}^{3+}, \mathrm{Sm}^{3+}$ et $\mathrm{Th}^{4+}$. Pour les lanthanides, l'hydrolyse augmente avec le numéro atomique et la diminution du rayon atomique. On montre que l'ion $\mathrm{Th}^{4+}$ subit l'hydrolyse de manière significative. Pour citer cet article : E. Bentouhami et al., C. R. Chimie 7 (2004).

(C) 2004 Académie des sciences. Published by Elsevier SAS. All rights reserved.

Keywords: Hydrolysis constants; Lanthanides (III); Potentiometry; Thorium(IV)

Mots clés : Constantes d'hydrolyse ; Lanthanides (III) ; Potentiométrie ; Thorium (IV)

\footnotetext{
* Corresponding author.

E-mail address: mustayeen.khan@univ-angers.fr (M.A. Khan).
} 


\section{Introduction}

The increase in the solvation of trivalent lanthanides is one of the consequences of lanthanide contractions as one moves along the series. Indeed, the decrease in the ionic radius results in an increase in the charge density and greater polarity of these cations, which produces an augmentation of the number of solvent molecules in the secondary sphere of coordination. The lanthanides are, therefore, quite sensitive towards the water contents of the medium and the aqueous ions $\mathrm{M}^{3+}$ are hydrolysed in water according to (Eq. (1)):

$\left[\mathrm{M}+\left(\mathrm{H}_{2} \mathrm{O}\right)_{n}\right]^{3+}+\mathrm{H}_{2} \mathrm{O} \rightleftharpoons\left[\mathrm{M}(\mathrm{OH})\left(\mathrm{H}_{2} \mathrm{O}\right)_{n-1}\right]^{2+}+\mathrm{H}_{3} \mathrm{O}^{+}$

It may be noted that for all equilibriums studied, the hydration water molecules have been neglected and the following simple notation has been adopted (Eq. (2)):

$\mathrm{M}^{n+}+\mathrm{H}_{2} \mathrm{O} \stackrel{\mathrm{K}_{11}^{*}}{\rightleftharpoons} \mathrm{M}(\mathrm{OH})^{(n-1)+}+\mathrm{H}^{+}$

where $K^{*}$ represents the overall hydrolysis constant:

$K_{11}^{*}=\frac{\left[\mathrm{M}(\mathrm{OH})^{(n-1)+}\right]\left[\mathrm{H}^{+}\right]}{\left[\mathrm{M}^{n+}\right]\left[\mathrm{H}_{2} \mathrm{O}\right]}$

which corresponds to Eq. (3):

$$
\begin{aligned}
& \stackrel{\beta_{10-1}}{\mathrm{M}^{n+}} \underset{\mathrm{MH}_{-1}{ }^{(n-1)+}+\mathrm{H}^{+}}{\beta_{10-1}}=\frac{\left[\mathrm{M}(\mathrm{OH})^{(n+1)+}\right]\left[\mathrm{H}^{+}\right]}{\left[\mathrm{M}^{n+}\right]\left[\mathrm{H}_{2} \mathrm{O}\right]}
\end{aligned}
$$

therefore $K_{11}^{*}=\frac{\beta_{10-1}}{\left[\mathrm{H}_{2} \mathrm{O}\right]}$, where $\beta$ is the overall equilibrium constant of the form $\beta_{\mathrm{MLH}}$ : M indicates metal, $\mathrm{L}$ ligand, and $\mathrm{H}$ proton (the negative sign denotes ion $\mathrm{OH}^{-}$).

On the other hand (Eq. (4)):

$$
\mathrm{M}^{n+}+\mathrm{OH}-\stackrel{\mathrm{K}_{10-1}}{\rightleftharpoons} \mathrm{M}(\mathrm{OH})^{(n-1)+}
$$

where $K$ is the stepwise stability constant:

$$
\begin{aligned}
& K_{10-1}=\frac{\left[\mathrm{M}(\mathrm{OH})^{(n+1)+}\right]}{\left[\mathrm{M}^{n+}\right]\left[\mathrm{OH}^{-}\right]}=\frac{\left[\mathrm{M}(\mathrm{OH})^{(n+1)+}\right]\left[\mathrm{H}^{+}\right]}{\left[\mathrm{M}^{n+}\right] K_{\mathrm{w}}}=\frac{\beta_{10-1}}{K_{\mathrm{w}}} \\
& \beta_{10-1}=K_{10-1} K_{\mathrm{w}}, \text { hence } \log \beta_{10-1}=\log K_{10-1}+\log K_{\mathrm{w}}
\end{aligned}
$$

or:

$$
-\log \beta_{10-1}=-\log K_{10-1}+\mathrm{p} K_{\mathrm{w}}
$$

\subsection{Lanthanides}

Biedermann et al. [1] studied the hydrolysis equilibrium of the lanthanide (III) ions. On the basis of $\mathrm{pH}$ measurements at constant ionic strength, maintained at $3 \mathrm{~mol} \mathrm{dm}^{-3}$ by $\mathrm{LiClO}_{4}$, they have reported weak hydrolysis in the $\mathrm{pH}$ range of $6.5-8.1$ and the formation of two species namely, $\mathrm{La}(\mathrm{OH})^{2+}\left(\log \beta_{10-1}=-10.1\right)$ and $\mathrm{La}_{6}(\mathrm{OH})_{10}{ }^{8+}\left(\log \beta_{60-10}=-78,7\right)$.

Yttrium mainly yields $\mathrm{M}(\mathrm{OH})^{2+}$ and to a lesser degree the $\mathrm{M}_{2}(\mathrm{OH})_{2}{ }^{4+}$ ions for $\mathrm{Ce}^{3+}$. However, only about $1 \%$ of the metal ion is hydrolysed without precipitate formation and consequently the main equilibrium appears to be [2]:

$3 \mathrm{Ce}^{3+}+5 \mathrm{H}_{2} \mathrm{O} \rightleftharpoons\left[\mathrm{Ce}_{3}(\mathrm{OH})_{5}\right]^{4+}+5 \mathrm{H}^{+}$

In aqueous solutions, the hydrolysis of trivalent lanthanides begins at a $\mathrm{pH}$ as low as 6. For example, for europium, $\log \beta_{10-1}$ varies between -7.8 at $I=0.1 \mathrm{~mol}$ $\mathrm{dm}^{-3}$ and -8.1 at $I=1 \mathrm{~mol} \mathrm{dm}^{-3}$ ) [3]. At the same time, various species can be formed, such as $\mathrm{Ln}(\mathrm{OH})_{2}{ }^{+}$, $\mathrm{Ln}(\mathrm{OH})_{3}, \mathrm{Ln}(\mathrm{OH})_{4}{ }^{-}, \mathrm{Ln}_{2}(\mathrm{OH})_{2}{ }^{4+}, \mathrm{Ln}_{3}(\mathrm{OH})_{5}{ }^{4+}$.

Schwinte et al. [4], under identical experimental conditions as in this work, obtained the methanolysis constants of some lanthanide ions. These results will be compared to the hydrolysis constants obtained in this work.

The results of references [3] and [4] appear to be quite credible, as they are the only studies carried out at constant ionic strength. It may be noticed that in the last years few results concerning the hydrolysis of lanthanide ions have been reported. This is certainly due to the complexity of models and to the difficulties met in this system.

The hydrolysis of trivalent lanthanides is gaining importance because of the increasing interest in the biological aspects of their complexes [5-7]. Webb et al. have studied the yttrium-EDTMP (ethylenediamine tetra(methyl phosphonic) acid) complexes in solution and have reported their formation constants [7]. Yttrium is not a lanthanide element, but with its atomic and ionic radii and its inorganic and biological chemistry, it is similar to the lanthanides [8]. Webb has indicated that Y-EDTMP complexes, like those of SmEDTMP, can be used for tumour localisation.

Mention can also be made of the luminescent properties of lanthanide organophosphates and their uses in industrial chemistry [9]. With all these considerations, 
knowledge of the hydrolysis constants of the lanthanides appears to be primordial and the present work may also establish a link between the lanthanides and the actinides.

\subsection{Thorium}

Actinides have a greater facility for complexing than lanthanides. This is because of exclusively ionic bonds in the latter, whereas the former are known to form covalent bonds using their $5 \mathrm{f}$ electrons. Binuclear species with hydroxo bridges as well as polymeric ones have been characterised [10]. Usherenko and Skorik [11] have determined the hydrolysis constants of thorium by potentiometric methods. These authors have reported the precipitation of polynuclear species at higher concentration $\left(C_{\mathrm{Th}^{4+}}=5 \times 10^{-3} \mathrm{~mol} \mathrm{dm}^{-3}\right)$. In a recent study on the aqueous solutions of Th(IV) using $\mathrm{X}$-ray absorption fine structure spectroscopy techniques, Rothe et al. have confirmed the presence of polynuclear or colloidal species at high thorium concentrations [12].

Milic and Suranji [13] have varied the concentration of thorium and the supporting electrolyte and have showed that at defined $\mathrm{pH}$ the rate of hydrolysis of thorium increases with its concentration. A potentiometric study of the hydrolysis of thorium (IV) in $0.1 \mathrm{~mol} \mathrm{dm}^{-3}$ potassium nitrate was carried out at $25^{\circ} \mathrm{C}$ by Brown and Ellis [14]. Using the Miniquad software, the best model retained is that of $\left[\mathrm{Th}(\mathrm{OH})^{3+}\right.$, $\left[\mathrm{Th}_{4}(\mathrm{OH})_{12}{ }^{4+}\right]$, and $\left[\mathrm{Th}_{6}(\mathrm{OH})_{15}{ }^{9+}\right]$, for which the formation constants are respectively: $-2.98,-30.55$ and -34.41 .

Davydov and Toropov [15] have reported the predominance of the species $\mathrm{Th}(\mathrm{OH})^{3+}$ at $\mathrm{pH}<4$, and for thorium concentration between $2 \times 10^{-5}$ and $2 \times 10^{-4} \mathrm{~mol} \mathrm{dm}^{-3}$. They have determined the first hydrolysis constant at ionic strength of $0.1 \mathrm{~mol} \mathrm{dm}^{-3}$ and at $20{ }^{\circ} \mathrm{C}$ in nitrate or perchlorate solutions of thorium and have calculated $\beta_{10-1}=(4.4 \pm 1.2) \times 10^{-5}$ or $\log \beta_{10-1}=-4.36$.

\subsection{Hydration energy of thorium (IV)}

The hydration energy of tetravalent thorium is much higher than those of lanthanides, which is due to its high charge density. Marcus [16] has calculated the value of $\Delta H_{\mathrm{hyd}}=-6000 \mathrm{~kJ} \mathrm{~mol}^{-1}$. Using thermodynamic data, he has evaluated for $r_{i}\left(\mathrm{Th}^{4+}\right)=1 \AA$ the thickness of the hydration layer at $2.36 \AA$ and the number of fixed water molecules at 14 . For the sake of comparison, he has given for lanthanum $\left(r_{i}=1.05 \AA\right.$ ), a thickness of hydration layer equal to $1.97 \AA$ and 10 for the number of fixed water molecules.

\subsection{Hydrolysis of lanthanides (III) and of thorium (IV)}

A preliminary study of hydrolysis of lanthanides (III) and thorium (IV) was undertaken and this consisted of titration of their metal salts solutions by an aqueous solution of sodium hydroxide. This is necessary in order to determine the hydrolysis constants that are to be injected as fixed values for the calculation of the stability constants of the complexes of lanthanides (III) and of thorium (IV) cations with (phenolic) monoand dimethylenephosphonic acids $[17,18]$ synthesised by Böhmer et al. [19]. The treatment by Sirko-P [20] and Superquad [21] of the different titration curves corresponding to different lanthanides permitted the interpretation of this increase of $\mathrm{H}^{+}$ions concentration by the following hydrolysis equilibriums:

$$
\begin{array}{lrl}
\mathrm{Ln}^{3+}+\mathrm{H}_{2} \mathrm{O} \rightleftharpoons \mathrm{Ln}(\mathrm{OH})^{2+}+\mathrm{H}^{+} & K_{1,1}^{*} \\
\mathrm{Ln}^{3+}+2 \mathrm{H}_{2} \mathrm{O} \rightleftharpoons \mathrm{Ln}(\mathrm{OH})_{2}^{+}+2 \mathrm{H}^{+} & K_{1,2}^{*} \\
\mathrm{Ln}^{3+}+3 \mathrm{H}_{2} \mathrm{O} \rightleftharpoons \mathrm{Ln}(\mathrm{OH})_{3}+3 \mathrm{H}^{+} & K^{*}{ }_{1,3}
\end{array}
$$

The overall hydrolysis constants $K_{1, i}^{*}$ are related to the overall stability constants, $\beta_{1,0, i}$ of the equilibrium: $\mathrm{Ln}^{3+}+i \mathrm{OH}^{-} \rightleftharpoons \mathrm{Ln}(\mathrm{OH})_{i}^{(3-i)+} \quad K_{1,10, i}^{*}$ $\beta_{1,0, i}=K_{\mathrm{w}} K_{1,0, \mathrm{i}}$ i i.e. $\log \beta_{1,0, \mathrm{i}}=\log K_{1,0, \mathrm{i}}+i \mathrm{p} K_{\mathrm{w}}$ where $K_{\mathrm{w}}$ is the hydrolysis constant of water at $25{ }^{\circ} \mathrm{C}$ $\left(K_{\mathrm{w}}=10^{-13,78}\right)$.

\section{Experimental section}

\subsection{Reagents}

The lanthanide (III) chlorides were commercial products p.a. (Janssen for Ce, Pr and Eu; Aldrich for $\mathrm{Nd}$; and Ventron for Sm). Solutions of $0.1 \mathrm{~mol} \mathrm{dm}^{-3}$ $\mathrm{NaClO}_{4} \cdot 6 \mathrm{H}_{2} \mathrm{O}$ (Fluka p.a.) and $1 \mathrm{~mol} \mathrm{dm}^{-3} \mathrm{NaOH}$ (Merck) were prepared with twice distilled and boiled water. The $\mathrm{pH}$ values of acid $\left(\mathrm{HClO}_{4}\right)$ or of base 
$(\mathrm{NaOH})$ were controlled with a precision $\mathrm{pH}$-meter. The solution of $\mathrm{NaClO}_{4}$ was added to the medium so that the ionic strength remains constant and equal to $0.1 \mathrm{~mol} \mathrm{dm}^{-3}$. Stock solutions of metals, $10^{-2} \mathrm{~mol}$ $\mathrm{dm}^{-3}$, were prepared by dissolving the metal (III) chlorides or metal (IV) nitrates in the solvent. These salts were dried at room temperature under vacuum before use and their stock solutions were standardised with EDTA [22] at pH 6 using xylenol orange as indicator. The final analytical concentration of metals was $10^{-3}$ mol dm${ }^{-3}$ for lanthanides and $10^{-4} \mathrm{~mol} \mathrm{dm}^{-3}$ for thorium. Higher concentrations result in precipitation.

\subsection{Potentiometric measurements}

The present investigation of metal-binding equilibriums was carried out as a series of potentiometric titrations at $25.0 \pm 0.1^{\circ} \mathrm{C}$ and constant ionic strength of $0.1 \mathrm{~mol} \mathrm{dm}^{-3}\left(\mathrm{NaClO}_{4}\right)$, adding $\mathrm{NaOH}$ to lanthanum chlorate and thorium nitrate solutions containing initially a slight excess of $\mathrm{HClO}_{4}$. In each titration the total metal concentration $\mathrm{M}$ was kept constant in order to make the calculations simple. Since the proton and metal concentrations were kept low compared with the concentration of perchlorate ion, the activity factors are assumed constant, and hence, for calculations, concentrations could be used instead of the activities. The titrating agent $\mathrm{NaOH}\left(1\right.$ or $\left.0.1 \mathrm{~mol} \mathrm{dm}^{-3}\right)$ used was stored in a polyethylene container equipped with a $\mathrm{CO}_{2}$ trap. All experiments were performed according to the method previously described [18].

Under the above experimental conditions, a hydrolysis study was undertaken for the lanthanide salts noted $\mathrm{Ln}^{3+}\left(\mathrm{Ce}^{3+}, \mathrm{Pr}^{3+}, \mathrm{Nd}^{3+}, \mathrm{Sm}^{3+}, \mathrm{Eu}^{3+}\right)$ and of thorium noted as $\mathrm{Th}^{4+} .10 \mathrm{ml}$ of an aqueous solution of $\mathrm{LnCl}_{3}\left(\mathrm{C}_{\mathrm{Ln}^{3+}}=10^{-3} \mathrm{~mol} \mathrm{dm}{ }^{-3}\right)$ and of $\mathrm{Th}\left(\mathrm{NO}_{3}\right)_{4}$ $\left(C_{\mathrm{Th}^{++}}=10^{-4} \mathrm{~mol} \mathrm{dm}^{-3}\right)$ were titrated against $\mathrm{NaOH}$ solutions of $0.1 \mathrm{~mol} \mathrm{dm}^{-3}$ and $0.01 \mathrm{~mol} \mathrm{dm}^{-3}$ respectively. This was carried out under an atmosphere of argon at $25^{\circ} \mathrm{C}$ and at constant ionic strength, $I=0.1 \mathrm{~mol} \mathrm{dm}^{-3}$, maintained by $\mathrm{NaClO}_{4}$.

\subsection{Computations}

The numerical treatment of the experimental data was carried out with the help of the softwares Sirko_P [20] and/or Superquad [21]. Several titrations, each including at least 150 pairs of data, were simultaneously processed with Sirko. The values reported in the tables are the mean values of the results of $N$ independent runs, given with their $95 \%$ confidence interval $\pm 2 \sigma_{N-1}$, where $\sigma$ is the standard deviation. $\mathrm{R}$-factor $\left(R_{\mathrm{f}}\right)$ is the result of a statistical test related to the fit between the experimental and calculated curves.

\section{Results}

\subsection{Lanthanides}

During titrations up to five equivalents of base were added. These curves are presented in Fig. 1 and the results of calculations are summarised in Table 1.

The absence of formation of $\mathrm{M}(\mathrm{OH})_{2}{ }^{+}$is to be noted for all lanthanide ions except for $\mathrm{Nd}^{3+}$. This means that this species probably exists in all cases but in negligible quantities, and consequently, it is rejected from the proposed model submitted for the calculations for refinement

The values of $\log \beta_{10-1}$ are between 6 and $7.5 \mathrm{log}$ units and take into consideration the presence of hydroxo and binuclear species. The values reported in the literature are between 5.5 and 10, but they have been calculated under the assumption that only $\mathrm{M}(\mathrm{OH})^{2+}$ is present within the interpreted zone. The uncertainties given for $\log \beta_{10-1}$ for our results and those of the

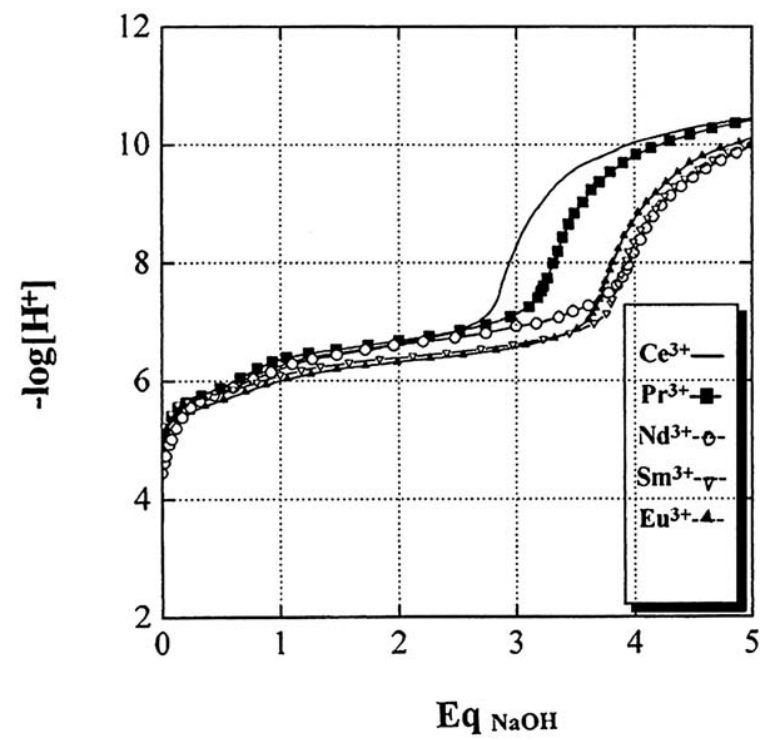

Fig. 1. Titration curves of different lanthanide (III) cations against $\mathrm{NaOH}$ in aqueous solution at $25{ }^{\circ} \mathrm{C}\left(C_{\mathrm{Ln}^{3+}}=10^{-3} \mathrm{~mol} \mathrm{dm}^{-3}\right.$ and $I=0.1 \mathrm{~mol} \mathrm{dm}^{-3} \mathrm{NaClO}_{4}$ ). 
Table 1

Logarithms of stability constants of the hydroxo species of lanthanide (III) cations $\left(25^{\circ} \mathrm{C}, I=0.1 \mathrm{~mol} \mathrm{dm}^{-3} \mathrm{NaClO}_{4}\right.$ and $\left.C_{\mathrm{Ln}^{3+}}=10^{-3} \mathrm{~mol} \mathrm{dm}^{-3}\right)$

\begin{tabular}{|c|c|c|c|c|c|}
\hline Cation & $x y z$ & species & $\log \beta_{x y z} \pm \sigma_{n-1}$ & $\mathrm{pH}$ range & $R_{\mathrm{f}}(\%)$ \\
\hline \multirow[t]{5}{*}{$\mathrm{Ce}^{3+}$} & $10-1$ & $\mathrm{Ce}(\mathrm{OH})^{2+}$ & $-6.87 \pm 0.08$ & $2.46-11.29$ & 1.8 \\
\hline & $10-3$ & $\mathrm{Ce}(\mathrm{OH})_{3}$ & $-19.82 \pm 0.05$ & & \\
\hline & $10-4$ & $\mathrm{Ce}(\mathrm{OH})_{4}^{-}$ & $-28.93 \pm 0.06$ & & \\
\hline & $20-3$ & $\mathrm{Ce}_{2}(\mathrm{OH})_{3}{ }^{3+}$ & $-15.93 \pm 0.09$ & & \\
\hline & $20-7$ & $\mathrm{Ce}_{2}(\mathrm{OH})_{7}^{-}$ & $-44.7 \pm 0.1$ & & \\
\hline \multirow[t]{5}{*}{$\operatorname{Pr}^{3+}$} & $10-1$ & $\operatorname{Pr}(\mathrm{OH})^{2+}$ & $-7.5 \pm 0.2$ & $2.43-11.27$ & 1.7 \\
\hline & $10-3$ & $\operatorname{Pr}(\mathrm{OH})_{3}$ & $-19.78 \pm 0.04$ & & \\
\hline & $10-4$ & $\operatorname{Pr}(\mathrm{OH})_{4}^{-}$ & $-29.84 \pm 0.05$ & & \\
\hline & $20-3$ & $\mathrm{Pr}_{2}(\mathrm{OH})_{3}{ }^{3+}$ & $-15.60 \pm 0.08$ & & \\
\hline & $20-5$ & $\mathrm{Pr}_{2}(\mathrm{OH})_{5}^{+}$ & $-29.42 \pm 0.09$ & & \\
\hline \multirow[t]{4}{*}{$\mathrm{Nd}^{3+}$} & $10-1$ & $\mathrm{Nd}(\mathrm{OH})^{2+}$ & $-6.19 \pm 0.06$ & $2.45-11.21$ & 2.6 \\
\hline & $10-2$ & $\mathrm{Nd}(\mathrm{OH})_{2}{ }^{+}$ & $-12.8 \pm 0.1$ & & \\
\hline & $10-3$ & $\mathrm{Nd}(\mathrm{OH})_{3}$ & $-20.1 \pm 0.2$ & & \\
\hline & $10-4$ & $\mathrm{Nd}(\mathrm{OH})_{4}^{-}$ & $-26.8 \pm 0.1$ & & \\
\hline \multirow[t]{4}{*}{$\mathrm{Sm}^{3+}$} & $10-1$ & $\mathrm{Sm}(\mathrm{OH})^{2+}$ & $-6.27 \pm 0.06$ & $2.40-11.22$ & 2.3 \\
\hline & $10-3$ & $\mathrm{Sm}(\mathrm{OH})_{3}$ & $-18.77 \pm 0.07$ & & \\
\hline & $10-4$ & $\mathrm{Sm}(\mathrm{OH})_{4}^{-}$ & $-26.11 \pm 0.07$ & & \\
\hline & $20-3$ & $\mathrm{Sm}_{2}(\mathrm{OH})_{3}{ }^{3+}$ & $-15.3 \pm 0.2$ & & \\
\hline \multirow[t]{4}{*}{$\mathrm{Eu}^{3+}$} & $10-1$ & $\mathrm{Eu}(\mathrm{OH})^{2+}$ & $-7.4 \pm 0.7$ & $2.50-11.20$ & 1.9 \\
\hline & $10-3$ & $\mathrm{Eu}(\mathrm{OH})_{3}$ & $-19.3 \pm 0.1$ & & \\
\hline & $10-4$ & $\mathrm{Eu}(\mathrm{OH})_{4}^{-}$ & $-26.2 \pm 0.1$ & & \\
\hline & $20-3$ & $\mathrm{Eu}_{2}(\mathrm{OH})_{3}{ }^{3+}$ & $-15.4 \pm 0.2$ & & \\
\hline
\end{tabular}

literature are centred on the same mean values. Eventually, Klungness and Byrne have recently published their results on the hydrolysis behaviour of the rare earths at 0.7 molar and zero ionic strength and have shown the dependence of hydrolysis constants on temperature and ionic strength [23]. Their values differ from ours by about one log unit. The following discussion will be based on our calculated values.

\subsection{Thorium}

Six base equivalents are necessary for titration in this case. These titration curves are illustrated in Fig. 2 and the results are presented in Table 2.

The interpretation of the experimental data leads to a very good agreement for the model $\mathrm{Th}(\mathrm{OH})_{3}{ }^{+}$, $\mathrm{Th}(\mathrm{OH})_{4}$ and $\mathrm{Th}_{2}(\mathrm{OH})_{7}{ }^{+}$. The $\mathrm{Th}(\mathrm{OH})^{3+}$ species was not retained for calculations because of its presence in extremely low quantities. This was previously reported by Moulin et al. [24], and all authors who have calculated the formation constant of this hydroxide, have reported very low values.

\section{Discussion}

\subsection{Nature of the species formed}

If one refers to Table 1, which presents all the results within $\mathrm{pH}$ range (2-11), several anionic mononuclear hydroxo complexes are observed for the lanthanides, namely $\mathrm{M}(\mathrm{OH})^{2+}, \mathrm{M}(\mathrm{OH})_{3}, \mathrm{M}(\mathrm{OH})_{4}^{-}$, $\mathrm{M}_{2}(\mathrm{OH})_{3}{ }^{3+}$ for $\mathrm{Ce}$, Pr, Sm et $\mathrm{Eu}$ and two binuclear hydroxo complexes $\mathrm{M}_{2}(\mathrm{OH})_{5}{ }^{+}$for $\mathrm{Pr}$ and $\mathrm{M}_{2}(\mathrm{OH})_{7}{ }^{-}$ for $\mathrm{Ce}$. In the case of thorium, the identified hydroxo complexes are $\mathrm{Th}(\mathrm{OH})^{3+}, \mathrm{Th}(\mathrm{OH})_{3}{ }^{+}, \mathrm{Th}(\mathrm{OH})_{4}$, and $\mathrm{Th}_{2}(\mathrm{OH})_{7}^{+}$.

The $\mathrm{Th}^{4+}$ cation undergoes hydrolysis to a greater extent than the cations of lanthanides as is evident from the high values of its calculated constants for the above species.

\subsection{Distribution curves of the complexes}

\subsubsection{Lanthanides}

The distribution curves for the hydroxo species for $C_{\mathrm{M}}=10^{-3} \mathrm{~mol} \mathrm{dm}^{-3}$, drawn with the help of software 

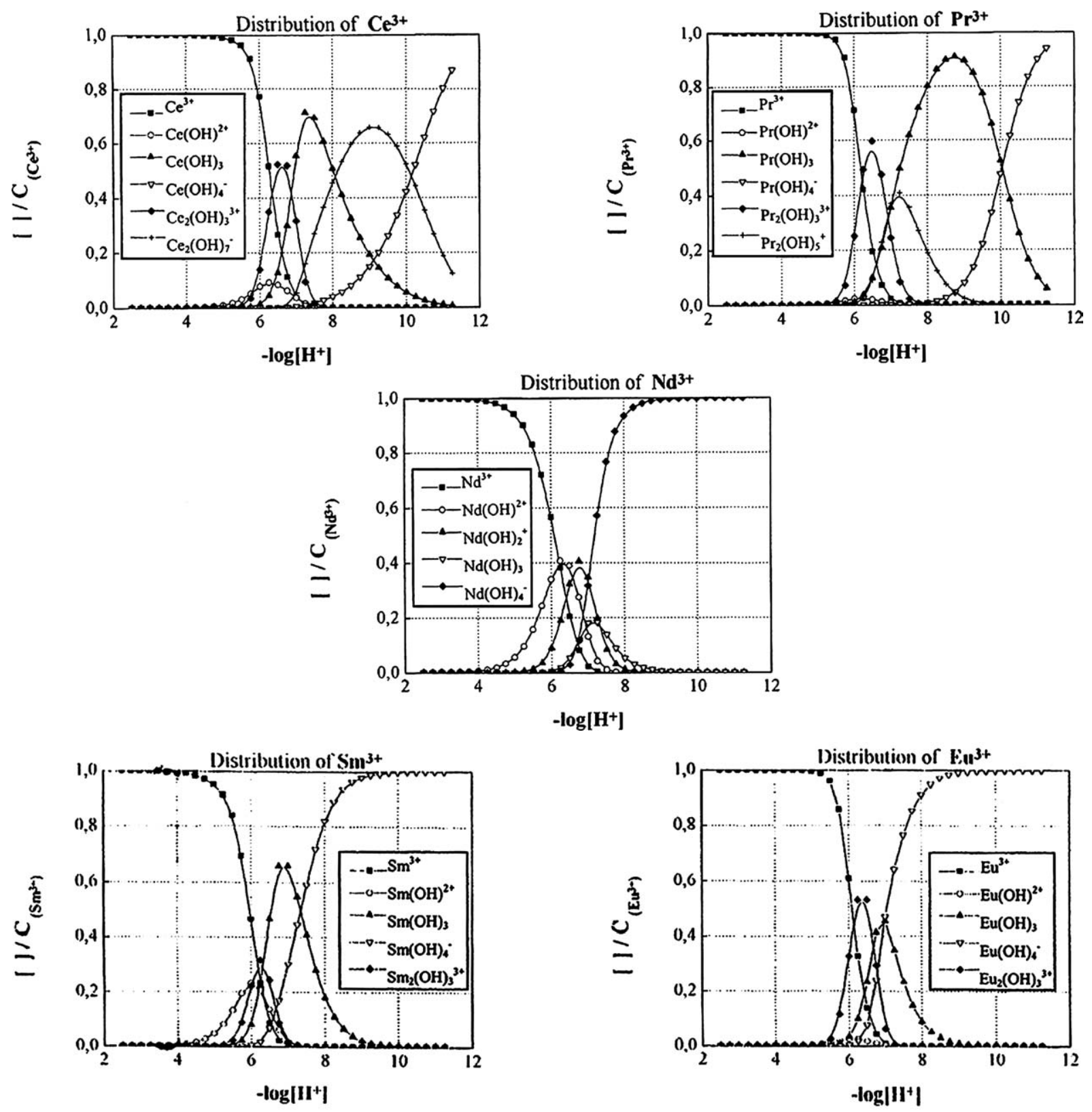

Fig. 2. Distribution curves of the hydroxo species of different lanthanide (III) cations as a function of $-\log \left[\mathrm{H}^{+}\right]$with $C_{\mathrm{Ln}}{ }^{3+}=10^{-3} \mathrm{~mol} \mathrm{dm}^{-3}$.

Haltafall [25], are shown in Fig. 3. It is seen that at $\mathrm{pH}$ 6 , the percentage of free cations is $75 \%$ for $\mathrm{Ce}^{3+}, \mathrm{Pr}^{3+}$, $60 \%$ for $\mathrm{Nd}^{3+}, \mathrm{Eu}^{3+}$, whereas for $\mathrm{Sm}^{3+}$ only $50 \%$ of free cations are present at this $\mathrm{pH}$. Therefore, the $\mathrm{Sm}^{3+}$ cation is the one most easily hydrolysed. In any case, the other species coexist within the range of $\mathrm{pH}$ be- tween 6 and 8 with a predominance for the neutral species $\mathrm{M}(\mathrm{OH})_{3}$.

\subsubsection{Thorium}

Fig. 4 gives the distribution curves for the various hydrolysed species formed with thorium. 
Table 2

Logarithms of stability constants of the hydroxo species of thorium (IV) cation $\left(25^{\circ} \mathrm{C}, I=0.1 \mathrm{~mol} \mathrm{dm}^{-3} \mathrm{NaClO}_{4}\right.$, and $\left.C_{\mathrm{Th}}{ }^{4+}=10^{-4} \mathrm{~mol} \mathrm{dm}^{-3}\right)$

\begin{tabular}{lllll}
\hline Cation & $x y z$ & Species & $\log \beta_{x y z} \pm \sigma_{n-1}$ & $\mathrm{pH} \mathrm{range}$ \\
\hline $\mathrm{Th}^{4+}$ & $10-2$ & $\mathrm{Th}(\mathrm{OH})_{2}{ }^{2+}$ & $-8.36 \pm 0.11$ & $3.824-9.726$ \\
& $10-3$ & $\mathrm{Th}(\mathrm{OH})_{3}{ }^{+}$ & $-11.63 \pm 0.09$ & 0.9 \\
& $10-4$ & $\mathrm{Th}(\mathrm{OH})_{4}$ & $-18.24 \pm 0.13$ & \\
& $20-7$ & $\mathrm{Th}_{2}(\mathrm{OH})_{7}{ }^{+}$ & $-24.32 \pm 0.08$ & \\
\hline
\end{tabular}

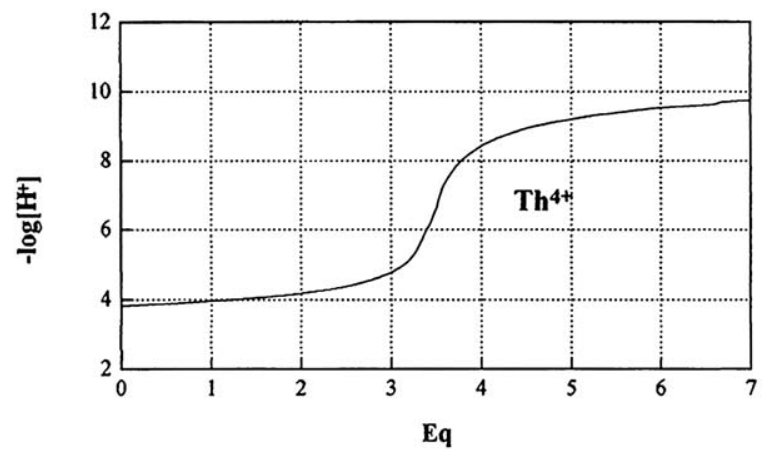

Fig. 3. Titration curves of thorium (IV) cation against $\mathrm{NaOH}$ in aqueous solution at $25^{\circ} \mathrm{C}\left(C_{\mathrm{Th}}{ }^{4+}=10^{-4} \mathrm{~mol} \mathrm{dm}{ }^{-3}\right.$ and $I=0.1 \mathrm{~mol}$ $\mathrm{dm}^{-3} \mathrm{NaClO}_{4}$ ).

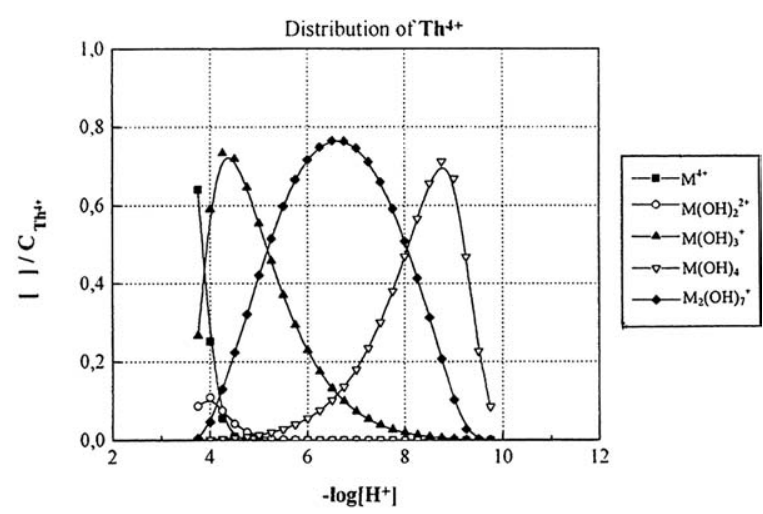

Fig. 4. Distribution curves of the hydroxo species of thorium (IV) as a function of $-\log \left[\mathrm{H}^{+}\right]$with $C_{\mathrm{Th}}{ }^{4+}=10^{-4} \mathrm{~mol} \mathrm{dm}^{-3}$.

At $\mathrm{pH}=4$, only $30 \%$ of $\mathrm{Th}^{4+}$ is in the free state, as most of it is transformed into $\mathrm{Th}(\mathrm{OH})_{3}{ }^{+}(60 \%)$ and $\mathrm{Th}(\mathrm{OH})_{2}{ }^{2+}(10 \%)$. The predominant species are quite well defined within precise zones of $\mathrm{pH}$. Thus, $\mathrm{Th}(\mathrm{OH})_{3}{ }^{+}$attains its maximum of formation $(70 \%)$ between $\mathrm{pH} 4$ and 5 , whereas at $\mathrm{pH}$ values between 8 and 9 , the neutral species $\mathrm{Th}(\mathrm{OH})_{4}$ is formed at $70 \%$. The binuclear species $\mathrm{Th}_{2}(\mathrm{OH})_{7}{ }^{+}$is formed predominantly, about $78 \%$, within a broad interval of $\mathrm{pH}$, between 5 and 8 . It may be remarked here that in the acidic zone, $\mathrm{pH}=4$, only $10 \%$ of the dihydroxo species, $\mathrm{Th}(\mathrm{OH})_{2}{ }^{2+}$ is formed and probably herein lies the
Table 3

Comparison of the solvolysis constants of lanthanide (III) in methanol and in aqueous solution

\begin{tabular}{|c|c|c|c|c|c|}
\hline \multirow{2}{*}{\multicolumn{2}{|c|}{ Cationxyz }} & \multirow{2}{*}{\multicolumn{2}{|c|}{$[\text { Methanolysis ] }]^{\mathrm{a}}$}} & \multirow{2}{*}{\multicolumn{2}{|c|}{ [Hydrolysis ] $^{\mathrm{b}}$}} \\
\hline & & & & & \\
\hline \multirow{6}{*}{$\overline{\operatorname{Pr}^{3+}}$} & $10-1$ & $\mathrm{Ln}(\mathrm{OR})^{2+}$ & -6.96 & $\mathrm{Ln}(\mathrm{OH})^{2+}$ & -7.49 \\
\hline & $10-2$ & $\mathrm{Ln}(\mathrm{OR})_{2}^{+}$ & -16.01 & - & - \\
\hline & $10-3$ & $\mathrm{Ln}(\mathrm{OR})_{3}$ & -26.53 & $\mathrm{Ln}(\mathrm{OH})_{3}$ & -19.78 \\
\hline & $10-4$ & $\mathrm{Ln}(\mathrm{OR})_{4}^{-}$ & -39.76 & $\mathrm{Ln}(\mathrm{OH})_{4}^{-}$ & -29.84 \\
\hline & $20-3$ & - & - & $\mathrm{Ln}_{2}(\mathrm{OH})_{3}{ }^{3+}$ & -15.60 \\
\hline & $20-5$ & $\mathrm{Ln}_{2}(\mathrm{OR})_{5}^{+}$ & -39.05 & $\mathrm{Ln}_{2}(\mathrm{OH})_{5}^{+}$ & -29.42 \\
\hline \multirow[t]{6}{*}{$\mathrm{Eu}^{3+}$} & $10-1$ & $\operatorname{Ln}(\mathrm{OR})^{2+}$ & -7.11 & $\mathrm{Ln}(\mathrm{OH})^{2+}$ & -7.39 \\
\hline & $10-2$ & $\mathrm{Ln}(\mathrm{OR})_{2}{ }^{+}$ & -15.27 & - & - \\
\hline & $10-3$ & $\mathrm{Ln}(\mathrm{OR})_{3}$ & -27.23 & $\mathrm{Ln}(\mathrm{OH})_{3}$ & -19.27 \\
\hline & $10-4$ & - & - & $\mathrm{Ln}(\mathrm{OH})_{4}^{-}$ & -26.25 \\
\hline & $20-3$ & $\operatorname{Ln}_{2}(\mathrm{OR})_{3}{ }^{3+}$ & -18.51 & $\mathrm{Ln}_{2}(\mathrm{OH})_{3}{ }^{3+}$ & -15.36 \\
\hline & $20-5$ & $\operatorname{Ln}_{2}(\mathrm{OR})_{5}^{+}$ & -38.66 & - & - \\
\hline
\end{tabular}

${ }^{\text {a }}$ Methanolysis: $C_{\mathrm{Ln}^{3+}}{ }^{3+}=10^{-3} \mathrm{~mol} \mathrm{dm}^{-3}, 25^{\circ} \mathrm{C}$, and $I=0.01 \mathrm{~mol}$ $\mathrm{dm}^{-3} \mathrm{Et}_{4} \mathrm{NClO}_{4}$.

${ }^{\mathrm{b}}$ Hydrolysis: $C_{\mathrm{Ln}}{ }^{3+}=10^{-3} \mathrm{~mol} \mathrm{dm}^{-3}, 25^{\circ} \mathrm{C}$, and $I=0.1 \mathrm{~mol} \mathrm{dm}^{-3}$ $\mathrm{NaClO}_{4}$.

explanation for the absence of the formation of the monohydroxo species $\mathrm{Th}(\mathrm{OH})^{3+}$.

\subsection{Comparative study}

\subsubsection{Lanthanides}

Table 3 collects the different species found by Schwinte [4] along with their methanolysis constants for $\mathrm{Pr}^{3+}$ and $\mathrm{Eu}^{3+}$. They are compared with the stoichiometry and the stability constants of the identified species with the same cations in this work.

A careful study of Table 3 highlights three main observations:

- (i) the nature of the species in methanolic solutions is identical to the species identified in the aqueous medium;

- (ii) the overall stability constant of the species $\mathrm{Ln}(\mathrm{OH})^{2+}$ is of the same magnitude whatever the solvent; 
Table 4

Comparison between the solvolysis constants of thorium (IV) in methanol and in aqueous solution

\begin{tabular}{|c|c|c|c|c|c|c|}
\hline$x y z$ & Solvent ${ }^{\mathrm{a}}$ & Species & $\log \beta_{\mathrm{xyz}}$ & Solvent ${ }^{\mathrm{b}}$ & Species & $\log \beta_{\mathrm{xyz}}$ \\
\hline $10-1$ & $\mathrm{CH}_{3} \mathrm{OH}$ & $\operatorname{Th}(\mathrm{OR})^{3+}$ & -3.36 & $\mathrm{H}_{2} \mathrm{O}$ & - & - \\
\hline $10-2$ & & - & & & $\mathrm{Th}(\mathrm{OH})_{2}{ }^{2+}$ & -8.36 \\
\hline $10-3$ & & $\mathrm{Th}(\mathrm{OR})_{3}{ }^{3+}$ & -15.94 & & $\mathrm{Th}(\mathrm{OH})_{3}{ }^{+}$ & -11.63 \\
\hline $10-4$ & & $\mathrm{Th}_{2}(\mathrm{OR})_{4}$ & -24.68 & & $\mathrm{Th}(\mathrm{OH})_{4}$ & -18.24 \\
\hline $20-5$ & & $\mathrm{Th}_{2}(\mathrm{OR})_{5}^{3+}$ & -22.6 & & - & - \\
\hline $20-7$ & & $\mathrm{Th}_{2}(\mathrm{OR})_{7}^{+}$ & -36.6 & & $\mathrm{Th}_{2}(\mathrm{OH})_{7}^{+}$ & -24.42 \\
\hline $20-9$ & & $\mathrm{Th}_{2}(\mathrm{OR})_{9}^{-}$ & -59.2 & & - & - \\
\hline
\end{tabular}

${ }^{\text {a }}$ Methanolysis: $C_{\mathrm{Ln}^{3+}}{ }^{3+} 10^{-3} \mathrm{~mol} \mathrm{dm}^{-3}, 25^{\circ} \mathrm{C}$ and $I=0,01 \mathrm{~mol} \mathrm{dm}^{-3} \mathrm{Et}_{4} \mathrm{NClO}_{4}$.

${ }^{\mathrm{b}}$ Hydrolysis: $C_{\mathrm{Th}}{ }^{4+}=10^{-4} \mathrm{~mol} \mathrm{dm}{ }^{-3}, 25^{\circ} \mathrm{C}$ and $I=0.1 \mathrm{~mol} \mathrm{dm}^{-3} \mathrm{NaClO}_{4}$.

- (iii) the solvolysis constants of the species present in alkaline medium are rather higher in the methanol medium.

\subsubsection{Thorium}

Different solvolysed species and their constants found by Schwinte [4] during her methanolysis study and those found in water in this hydrolysis study are collected in Table 4. The species $\mathrm{Th}(\mathrm{OH})^{3+}$ is not observed whereas $\mathrm{Th}(\mathrm{OR})^{3+}$ exists. It is concluded that thorium is more easily solvolysed in the aqueous medium than in methanol. This is supported by the fact that a second hydrolysed species $\operatorname{Th}(\mathrm{OH})_{2}{ }^{2+}$ is observed, which is not the case in methanol.

Nevertheless, it is remarked that in the same $\mathrm{pH}$ range, globally, the nature of species in methanol conforms to those found in this study, i.e., in water. The only constant that is frequently cited in the literature in an hydrolysis study of thorium in aqueous medium is that of $\mathrm{Th}(\mathrm{OH})_{2}{ }^{2+}$. It varies between -6.5 and -8.0 , which is in agreement with the value found in this study, equal to -8.36 .

\section{Conclusion}

The literature offers a number of values for the hydrolysis constants but they have to be compared with extreme caution, as they are determined under different experimental conditions. This is especially the case as the $\mathrm{pH}$ range studied is quite limited up to now.

The tendency for hydrolysis increases with the increase of atomic number and the contraction of the ionic radius. Normally, the actinides are more readily hydrolysed in aqueous medium than the lanthanides and this is confirmed in this study. Strictly, actinides (III) should be compared to lanthanides (III), however, the former are very similar to the latter and so in this work thorium (IV) has been compared to lanthanides (III) in order to observe the influence of charge on the complexing ability of the ion. The $\mathrm{Th}^{4+}$ ion is more resistant to hydrolysis than the rest of the actinides, but still it undergoes significant hydrolysis for $\mathrm{pH}$ values of 3 and onwards. Different species, more or less complex, are formed depending either on the conditions of $\mathrm{pH}$ or on the anions that are present and on their concentrations. Mainly polymeric hydroxo species are formed.

\section{References}

[1] G. Biedermann, L. Ciavatta, Acta Chem, Scand. 15 (1961) 1366.

[2] F.A. Cotton, G. Wilkinson, Advanced Inorganic Chemistry, 4th Ed, John Wiley and Sons Inc., New York, 1980, p. 991.

[3] M.S. Caceci, G.R. Choppin, Radiochem. Acta 33 (1983) 101.

[4] P. Schwinte, Doctoral Thesis Louis-Pasteur University, Strasbourg, 1995.

[5] A.S. Alberts, S.W. Brighton, P. Kempf, W.K. Louw, A.V. Beek, V. Kritzenger, H.P. Westerink, A.J. Vanrensburg, J. Nucl. Med. 36 (1995) 1417.

[6] G.C. de Witt, P.M. May, J. Webb, G. Hefter, BioMetals 9 (1996) 351.

[7] G.C. de Witt, P.M. May, J. Webb, G. Hefter, Inorg. Chim. Acta 37 (1998) 275.

[8] C.H. Evans, Biochemistry of the Lanthanides, Plenum Press, New York, 1990.

[9] I.L.V. Rosa, E.J. Nassar, O.A. Serra, J. Alloys Compds 275277 (1998) 315.

[10] M. Magini, Acta Chem. Scand. 30A (1976) 437.

[11] L.N. Usherenko, N.A. Skorik, Russ. J. Inorg. Chem. 17 (1972) 1533.

[12] J. Rothe, M.A. Denecke, V. Neck, R. Muller, J.I. Kim, Inorg. Chem. 41 (2002) 249.

[13] N.B. Milic, P.M. Suranji, Can. J. Chem. 60 (1982) 1298.

[14] P.L. Brown, J. Ellis, R.N. Sylva, J. Chem. Soc. Dalton Trans. 31 (1983). 
[15] J.P. Davydov, I.G. Toporov, Zh. Neorg. Khim. 31 (1986) 351.

[16] Y. Marcus, Pure Appl. Chem. 59 (1987) 1093.

[17] E. Bentouhami, G.M. Bouet, M.A. Khan, Phosphorus, Sulfur and Silicon 1783 (2003) 90.

[18] E. Bentouhami, G.M. Bouet, M.A. Khan, Talanta 57 (2002) 545

[19] V. Böhmer, W. Vogt, S. Chafaa, J. Meullemeestre, M.J. Schwing, F. Vierling, Helv. Chim. Acta 76 (1993) 139.

[20] V.I. Vetrogon, N.G. Lukyanenko, M.J. Schwing-Weill, F. Arnaud-Neu, Talanta 41 (1994) 2105
[21] P. Gans, A. Sabatini, A. Vacca, Inorg. Chim. Acta 79 (1983) 219.

[22] E. Merck, Méthodes d'analyses complexométriques par les titriplex, Merck, Darmstadt, Germany, 1964.

[23] G.D. Klungness, R.H. Byrne, Polyhedron 19 (2000) 99.

[24] C. Moulin, B. Amekraz, S. Hubert, V. Moulin, Anal. Chim. Acta 441 (2001) 269.

[25] N. Ingri, W. Kakolowicz, L.G. Sillen, B. Warnqvist, Talanta 14 (1967) 1261. 